\title{
Calcitonin Gene-Related Peptide Inhibits Nonadrenergic Noncholinergic Contraction of Guinea Pig Distal Colon
}

\author{
Shu-ichi Kojima \\ Department of Pharmacology, Dokkyo University School of Medicine, Mibu, Tochigi 321-02, Japan \\ Received November 13, 1996 Accepted January 17, 1997
}

\begin{abstract}
In the guinea pig distal colon, calcitonin gene-related peptide (CGRP, $0.1-30 \mathrm{nM}$ ) produced a concentration-dependent inhibition in electrically-evoked nonadrenergic noncholinergic (NANC) contractions and exogenous substance $\mathbf{P}$-induced contractions. Both the inhibitory actions of CGRP were insensitive to human CGRP $(8-37)(1-3 \mu \mathrm{M})$, a CGRP ${ }_{1}$ receptor antagonist. These results indicate that in the distal colon, CGRP inhibits electrically-evoked NANC contraction through a postjunctional mechanism, in contrast to our previously described results that CGRP enhances the NANC contraction of guinea pig proximal colon via a prejunctinal mechanism.
\end{abstract}

Keywords: Calcitonin gene-related peptide (CGRP), Nonadrenergic noncholinergic (NANC) transmission, Colon (guinea pig)

Calcitonin gene-related peptide (CGRP), a 37 amino acid peptide has been identified as a likely transmitter candidate in the enteric nervous system (1), but the exact role of CGRP in the control of intestinal motility is still not clear. Recently, we have shown that in the guinea pig proximal colon, CGRP facilitates neuromuscular nonadrenergic noncholinergic (NANC) transmission via a prejunctional mechanism and that the CGRP enhancing effect was insensitive to micromolar concentrations of human CGRP (hCGRP)(8-37), a CGRP ${ }_{1}$-receptor antagonist (2). It is, however, unclear whether CGRP modifies NANC neurotransmission in other regions of the intestine. Our present study reveals that in the distal regions of guinea pig colon, CGRP produces an inhibition of electrical field stimulation (EFS)-evoked NANC contraction via a post-junctional mechanism, in contrast to the proximal regions of guinea pig colon.

Male Dunkin Hartley guinea pigs $(210-400 \mathrm{~g})$ were anesthetized with enflurane and bled. Segments of the distal colon were removed and strips of mucosa-free longitudinal muscle were prepared as described in a previous study (3). The strips were set up longitudinally under a $0.5-\mathrm{g}$ load in $15-\mathrm{ml}$ tissue baths filled with a modified Tyrode solution (136.8 $\mathrm{mM} \mathrm{NaCl}, 2.7 \mathrm{mM} \mathrm{KCl}, 1.8 \mathrm{mM}$ $\mathrm{CaCl}_{2}, 1.05 \mathrm{mM} \mathrm{MgCl}, 0.42 \mathrm{mM} \mathrm{NaH} \mathrm{PO}_{4}, 11.9 \mathrm{mM}$ $\mathrm{NaHCO}_{3}, 5.56 \mathrm{mM}$ glucose and $0.12 \mathrm{mM}$ ascorbic acid, pH 7.4) at $37^{\circ} \mathrm{C}$ and bubbled with $5 \% \mathrm{CO}_{2}, 95 \% \mathrm{O}_{2}$. In all experiments, the modified Tyrode solution also contained atropine $(0.3 \mu \mathrm{M})$, guanethidine $(5 \mu \mathrm{M})$, indomethacin (3 $\mu \mathrm{M})$ and hexamethonium (100 $\mu \mathrm{M})$. To obtain nervemediated contractions of guinea pig colon after a $60-\mathrm{min}$ equilibration, the distal colon was stimulated with $10-\mathrm{sec}$ trains of pulses of $0.3-\mathrm{msec}$ width, $15-35-\mathrm{v}$ amplitude at $3 \mathrm{~Hz}$ using a stimulator (SEN-7203; Nihon Kohden, Tokyo). Our previously described methods (2) were used to evaluate the effects of CGRP or antagonists on EFSevoked or substance P-induced contractions. The effects of CGRP and antagonists on the EFS-induced contractions were expressed as a percentage of the mean of the 3 consecutive control responses prior to drug addition. The percentage effects of CGRP were plotted as mean values to obtain $\log$ concentration-response curves. The $\mathrm{pIC}_{50}$ $(-\log \mathrm{M})$ of CGRP was determined from each curve, according to the method of Van Rossum (4). The results are expressed as the mean with S.E.M., and statistical significance of values was determined by Student's paired $t$-test or Dunnett's multi-comparison test when appropriate. Significance was accepted at the $0.05 \%$ level.

The following drugs were used: atropine sulphate, hexamethonium chloride dihydrate (Wako, Osaka); guanethidine sulphate (Ciba, Basel, Switzerland); tetrodotoxin (Sankyo, Tokyo); substance P, CGRP (human $\alpha$-CGRP), hCGRP(8-37) (Peptide Institute, Osaka), indomethacin (Sigma, St. Louis, MO, USA); FK $888\{(2-(N-M e) i n d o l i l)-c o-H y p-N a l-N M e-B z l\}$, a gift from Fujisawa Pharmaceutical Co., Ltd., Osaka); 


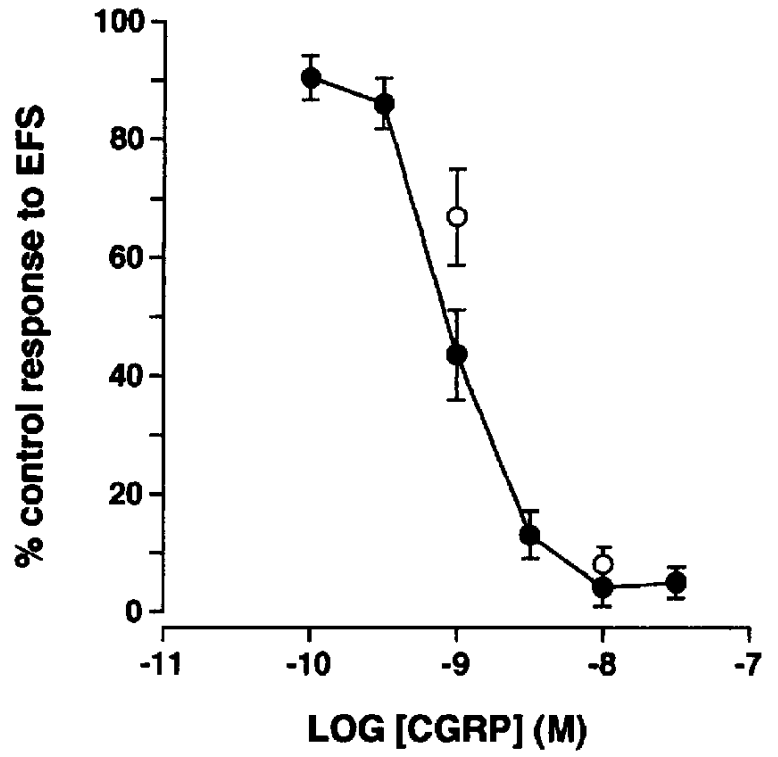

Fig. 1. Concentration-response curves for the inhibitory effect of CGRP on electrically-evoked contractions of guinea pig distal colon (O) and the effects of $1 \mu \mathrm{M}$ hCGRP $(8-37)$ on the inhibition of the electrically-evoked contractions by CGRP(1 or $10 \mathrm{nM}, O)$. Each point represents the mean \pm S.E.M. of 6-8 experiments. hCGRP $(8-37)$ did not affect the inhibitory effect of CGRP $(P>0.05)$. Atropine $(0.3 \mu \mathrm{M})$, guanethidine $(5 \mu \mathrm{M})$, hexamethonium $(100 \mu \mathrm{M})$ and indomethacin $(3 \mu \mathrm{M})$ were present throughout the experiments.

SR $48968\{(S)-N$-methyl- $N$-[4-acetylamino-4-phenyl-piperidino)-2-(3,4-dichlorophenyl)butyl]benzamide\}, a gift from Dr. X. Emonds-Alt (Sanofi Recherche, Montpellier, France).

EFS $(3 \mathrm{~Hz}, 0.3 \mathrm{msec}$ for the $10 \mathrm{sec})$ of the longitudinal muscle of the guinea pig distal colon evoked reproducible submaximal contractions (the amplitude of which was $26.4 \pm 1.3 \%$ of the substance $P(300 \mathrm{nM}, \mathrm{n}=8)$-induced maximal contraction). The contractile responses to EFS were abolished by tetrodotoxin $(0.3 \mu \mathrm{M})$, but partially reduced by the addition of the tachykinin $\mathrm{NK}_{1}$-receptor antagonist FK $888(10 \mu \mathrm{M})$ plus the $\mathrm{NK}_{2}$-receptor antagonist SR $48968(3 \mu \mathrm{M})(56.7 \pm 3.8 \%, \mathrm{n}=6$, compared to pre-drug control, $\mathrm{P}<0.05)$. CGRP $(0.1-30 \mathrm{nM})$ produced a concentration-dependent inhibition in the electrically-evoked contractions, with a maximal effect of $4.3 \pm 3.2 \%$ at $10 \mathrm{nM}$, resulting in $\mathrm{pIC}_{50}$ values of $9.04 \pm 0.08$ ( $n=8$, Fig. 1). In this concentration-range, CGRP did not have any significant influence on basal tone. Calcitonin $(1-100 \mathrm{nM}, \mathrm{n}=4)$ did not affect the EFS-evoked contractions of the distal colon (data not shown). hCGRP(8-37) $(1 \mu \mathrm{M})$, a $\mathrm{CGRP}_{1}$-receptor antagonist, was ineffective against the inhibitory effect of CGRP (1 or $10 \mathrm{nM}$ ) on EFS-evoked contractions (Fig. 1). Submaximal contractions of the distal colon were evoked by substance $\mathrm{P}(1-10 \mathrm{nM})$ before and during exposure to

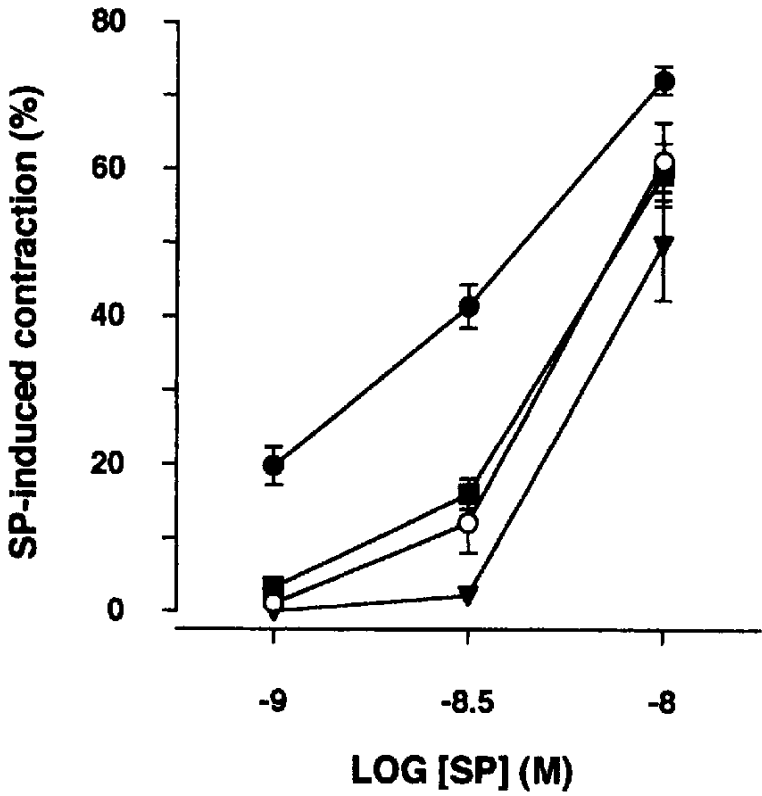

Fig. 2. The effect of CGRP ( 1 or $3 \mathrm{nM}$ ) on substance $P$ (SP, $1-10$ $\mathrm{nM})$-induced contractions in the absence and presence of hCGRP $(8-37)(3 \mu \mathrm{M})$; control (O), 1 nM CGRP (O), 3 nM CGRP ( $)$ ), $1 \mathrm{nM}$ CGRP/hCGRP(8-37) ( $\square$ ). Each point represents the mean \pm S.E.M. of $6-8$ experiments.

CGRP (1-3 nM). As shown in Fig. 2, CGRP inhibited the substance $P$-induced contractions in a concentrationdependent manner. hCGRP $(8-37)(3 \mu \mathrm{M})$ was without affect on the inhibitory effect of CGRP on substance Pinduced contractions.

In the presence of atropine, guanethidine and hexamethonium, EFS evoked tetrodotoxin-sensitive contractions of guinea pig distal colon, indicating the activation of postganglionic NANC excitatory neurons. The present findings show that the NANC contraction of the distal colon evoked by EFS was inhibited in the presence of CGRP. Although the exact mechanism of the inhibitory action of CGRP was not assessed in this study, several elements strongly suggest that the inhibitory effect of CGRP on EFS-evoked NANC contraction of the distal colon can be accounted for by a postjunctional smooth muscle depressant action that does not involve the activation of $\mathrm{CGRP}_{1}$ receptors.

The evidence favoring this interpretation can be summarized as follows: i) the contractile responses to exogeous substance $\mathrm{P}$ and EFS are inhibited by similar concentrations of CGRP, and both the inhibitory actions of CGRP are resistant to hCGRP(8-37); ii) the direct postjunctional effect of CGRP on the circular muscle of the guinea pig colon is inhibitory, producing membrane hyperpolarization and relaxation (5). The postjunctional inhibitory effect of CGRP on EFS-evoked NANC contraction appear to be due to a non-specific effect, since 
CGRP inhibited substance P-induced contractions or neuromedin B-induced contractions (data not shown). In contrast to the present results, we have recently shown that CGRP enhances the electrically-evoked NANC contraction of guinea pig proximal colon via a presynaptic mechanism (2). The reasons for this differential effect of CGRP on NANC neurotransmission in the proximal and distal colon are unknown, but it will be important to establish whether the differential effects of CGRP are due to transmission from different types of NANC excitatory neurons. Moreover, additional mechanisms which may vary with differences in CGRP receptor reserves or receptor subtypes in different regions of the colon must also be borne in mind. In conclusion, the present results indicate that CGRP has differential effects on NANC neurotransmission in the proximal and distal colon of guinea pigs via a pre- or post-junctional mechanism.

\section{REFERENCES}

1 Goyal RK and Hirano I: The enteric nervous system. N Engl J Med 334, 1106-1115 (1996)

2 Kojima S and Shimo Y: Calcitonin gene-related peptide (CGRP)-enhanced non-adrenergic non-cholinergic contraction of guinea-pig proximal colon. Br J Pharmacol 115, 1290-1294 (1995)

3 Kojima S: Characterization of 5-hydroxytryptamine-induced relaxations of guinea-pig proximal colon. Arch Int Pharmacodyn Ther 313, 23-32 (1991)

4 Van Rossum JM: Cumulative dose-response curves. II. Technique for the making of dose-response curves in isolated organs and the evaluation of drug parameters. Arch Int Pharmacodyn Ther 143, 299-330 (1963)

5 Maggi CA, Giuliani S and Zagorodnyuk V: CGRP in the circular muscle of guinea-pig colon: role as inhibitory transmitter and mechanisms of relaxation. Regul Pept 61, 27-36 (1996) 